\title{
Application of dexmedetomidine for lung injury in elderly patients undergoing one-lung ventilation
}

\author{
Zhi-Guo Shi ${ }^{1}$, Wei-Dong $\mathrm{Mi}^{2}$
}

${ }^{1}$ Department of Anesthesiology, Beijing Chest Hospital, Capital Medical University, China 2Department of Anesthesiology, Chinese PLA General Hospital, China

Submitted: 22 March 2019

Accepted: 1 October 2019

Arch Med Sci

DOI: https://doi.org/10.5114/aoms.2020.94944

Copyright $\odot 2020$ Termedia \& Banach

\begin{abstract}
Introduction: This study aimed to evaluate the effects of dexmedetomidine (DEX) on lung injury, the oxygenation index and perioperative pulmonary complications in elderly patients who underwent thoracotomy with one-lung ventilation (OLV).

Material and methods: A total of 120 elderly patients with lung cancer were included in the present study. According to the random number table method, these patients were randomly divided into two groups: group D and group C. Patients in group D were intravenously pumped with $0.5 \mu \mathrm{g} / \mathrm{kg} / \mathrm{h}$ of DEX before anesthesia. The infusion was completed within 15 minutes, and anesthesia was induced by venous injection. Patients in group $C$ were pumped with equal volumes of normal saline.

Results: $A t T_{2}$ and $T_{3}$, compared with group $C$, group $D$ had a significant decrease in cardiac index, mean arterial pressure and central venous pressure $(p<0.05)$. At $T_{2}, T_{3}$ and $T_{4}$, compared with group $C$, group $D$ had a significant increase in $\mathrm{pH}$ and $\mathrm{PaO}_{2}(p<0.05)$. At $\mathrm{T}_{2}, \mathrm{~T}_{3}$ and $\mathrm{T}_{4}$, compared with group C, group D had a significant decrease in Qs/Qt $(p<0.05)$. At $\mathrm{T}_{6}$, compared with group $C$, group $D$ had a significant decrease in the supernatant of bronchoalveolar lavage fluid of tumor necrosis factor- $\alpha$ and interleukin 6 $(p<0.05)$. At $T_{5}$, compared with group $C$, group $D$ had a significant decrease in Visual Analogue Scale score $(p<0.05)$, and a significant increase in Ramsay Sedation Scale score $(p<0.05)$, and the number of respiratory and cardiovascular events also decreased $(p<0.05)$.

Conclusions: In elderly patients, dexmedetomidine can reduce Qs/Qt and increase $\mathrm{PaO}_{2}$ during OLV in surgery. It can reduce lung injury. Moreover, DEX reduced respiratory and cardiovascular complications in the perioperative period.
\end{abstract}

Key words: one-lung ventilation, dexmedetomidine, lung injury.

\section{Introduction}

At present, the incidence of lung cancer ranks first among malignant tumors, the age of peak onset is within 60-79 years old, and thoracic surgery remains the main treatment for early lung cancer [1].

In the anesthesia for thoracic surgery, one-lung ventilation (OLV) is a very important method of ventilation. It can well maintain the ventilation for patients and prevent this from affecting the operative procedure [2]. However, OLV is likely to cause lung injury and hypoxemia [3]. Although the incidence of moderate to severe postoperative pulmonary

\author{
Corresponding author: \\ Wei-Dong Mi \\ Department of Anesthesiology \\ Chinese PLA General Hospital \\ China \\ E-mail: \\ miweidong1838@163.com
}


complications (PPCs) after thoracic surgery is not known accurately, it ranges between 15 and 32\% in studies with large sample sizes [4-6].

The mechanism of OLV causing lung injury [7] is divided into four types: pressure injury, volume trauma, injury related to collapse of alveoli and the biological injury caused by the above lung injuries. It has been reported [8] that the release of inflammatory cytokines from the alveolar surface can be triggered by mechanical ventilation for a few minutes, which further leads to local inflammatory response of the lung. Collapse of the lung on the operated side will cause ischemic/ hypoxic injury of this side of the lung. When ventilation is resumed for the two lungs, there will be an increase in the blood in the pulmonary vascular bed on the operated side. As a result, free oxygen radicals and some harmful cytokines will be produced, which causes ischemia-reperfusion injury of the lung on the operated side [9].

Biological injury of the lung as one mechanism of lung injury plays a very important role, and so does the oxidative stress response [10]. Also, OLVrelated hypoxemia is closely correlated to intraoperative intrapulmonary shunt fraction (Qs/Qt) [10]. During OLV, reducing lung injury and Qs/Qt caused by mechanical ventilation is highly necessary.

With age, the immune function of the elderly decreases, and the physiological functions of the organs gradually attenuate. In elderly patients, the physiology of respiratory and circulatory systems significantly changes during anesthesia with OLV for thoracotomy $[7,11,12]$. In elderly patients, the incidence of perioperative complications during thoracotomy significantly increases due to the attenuation of physiological function. Elderly patients undergoing thoracotomy are more likely to develop pulmonary complications during the perioperative period. Shiono et al. reported that $[10,13] 5.1-6.1 \%$ of elderly patients develop pulmonary infection after thoracotomy. Advanced age is already identified as an independent risk factor of lung injury caused by mechanical ventilation [14].

Dexmedetomidine (DEX) is a highly selective $\alpha 2$ adrenergic receptor agonist. It has effects of analgesia, anti-anxiety, anti-sympathetic, inhibition of saliva secretion, inhibition of the stress response and hemodynamic stability, and can reduce the occurrence of tissue injury by inhibiting inflammatory reactions [15]. There are a large number of $\alpha 2$-receptors on the bronchial mucosa. It has been shown [10] that DEX acts on the $\alpha 2$-receptors, inhibits the inflammatory response, and relieves the ischemia/reperfusion injury, thereby exerting a protective effect on the organs $[16,17]$.

However, the use of DEX in elderly patients receiving OLV during anesthesia has not been reported. The physiological mechanism is unique in elderly patients receiving OLV and these patients have a higher risk of perioperative complications [13]. This study investigated the use of DEX in elderly patients receiving OLV during thoracotomy. The authors hypothesized that DEX may reduce lung injury and reduce respiratory as well as cardiovascular complications in the perioperative period in elderly patients.

\section{Material and methods}

\section{Data and methods}

This study was approved by the Ethics Committee of our hospital, and all patients provided signed informed consent.

The patients were recruited from Beijing Chest Hospital affiliated to Capital Medical University from October 2015 to December 2018. Inclusion criteria: (1) aged 60-86 years old; (2) grade II or III according to American Society of Anesthesiologists (ASA) physical status classification system; (3) no history of long-term heavy smoking; (4) no apparent abnormalities of heart, liver and kidney functions. Exclusion criteria: (1) preoperative longterm history of hormone therapy; (2) preoperative arterial oxygen saturation $\left(\mathrm{SpO}_{2}\right)$ below $90 \%$; (3) difficult airway; (4) already combined with pulmonary insufficiency, such as acute upper respiratory tract diseases, chronic obstructive pulmonary disease (COPD) or asthma; (5) intraoperative blood transfusions exceeding $400 \mathrm{ml}$.

These patients were randomly divided into two groups ( $n=60$ ) using the random number table method: the DEX group (group D), and the control group (group C). At 30 minutes before anesthesia, patients were intramuscularly injected with $1 \mathrm{mg}$ of penehyclidine hydrochloride. After the patient was transferred to the operation room, the vein access was opened, and the electrocardiogram (ECG), $\mathrm{SpO}_{2}$, mean arterial pressure (MAP) and bispectral index (BIS) were routinely monitored. At 15 minutes before anesthesia induction, patients in group D were intravenously injected with DEX at a rate of $0.5 \mu \mathrm{g} / \mathrm{kg} / \mathrm{h}$ until sternal closure. Patients in group C were intravenously injected with equal volumes of normal saline.

Anesthesia induction: Patients were successively and intravenously injected with $0.4 \mu \mathrm{g} / \mathrm{kg}$ of sufentanil and $0.04 \mathrm{mg} / \mathrm{kg}$ of midazolam. Then, they received a target-controlled infusion (TCl) of propofol (target plasma concentration: $2.5-3.0 \mu \mathrm{g} / \mathrm{ml}$ ) and $0.2 \mathrm{mg} / \mathrm{kg}$ of cisatracurium, and dual-lumen bronchial intubation was performed. Subsequently, the fiberbronchoscope was located, and mechanical ventilation was performed. Parameters for two-lung ventilation: tidal volume, 8-10 $\mathrm{ml} / \mathrm{kg}$ (based on standard weight); frequency of respiration, 10-14/min; inspiratory-to-expirato- 
ry ratio, 1.0 : 1.5. Parameters for OLV: tidal volume, $7 \mathrm{ml} / \mathrm{kg}$; frequency of respiration, 12-16/min; inspiratory-to-expiratory ratio, $1: 1.5$. Target-controlled infusion of remifentanil hydrochloride (target plasma concentration: $2.5-3.0 \mathrm{ng} / \mathrm{ml}$ ) was performed.

Anesthetic maintenance: $\mathrm{TCl}$ of propofol was performed intraoperatively to achieve the target plasma concentration of $2 \sim 3.5 \mu \mathrm{g} / \mathrm{kg}$. Remifentanil hydrochloride (target plasma concentration 2.5 3 $\mathrm{ng} / \mathrm{ml}$ ) was injected through $\mathrm{TCl}$, and intravenous injection of cisatracurium besylate $(5 \mathrm{mg})$ was performed if necessary. Bispectral index was maintained within 40-60, heart rate $(H R)$ within 60-100 beats/min, and MAP fluctuation not above $20 \%$ of the baseline. If MAP was higher by over $20 \%$ of the baseline for more than one minute and the influence of anesthetic depth was excluded, $12.5 \mathrm{mg}$ of urapidil was given through intravenous injection; if MAP was lower by over $20 \%$ of the baseline for more than one minute and infusion of fluid $(50 \mathrm{ml})$ within 5-10 minutes took no effect, then after excluding the influence of anesthetic depth, $6 \mathrm{mg}$ of ephedrine was intravenously injected; if $\mathrm{HR} \leq 50$ beats/min or $\geq 100$ beats/min, then atropine $(0.2 \mathrm{mg})$ and esmolol $(5 \mathrm{mg})$ were intravenously injected, respectively. All these vasoactive drugs could be repeatedly used. If these measures still failed to stabilize the circulation, the patients were excluded from the experiment. A bypass collateral circulation monitoring system was used. Peak airway pressure $\left(P_{\text {peak }}\right)$, platform pressure $\left(\mathrm{P}_{\text {plat }}\right)$ and dynamic pulmonary compliance $\left(C_{\text {dyn }}\right)$ were recorded every five minutes.

After surgery, the patients were given patient-controlled intravenous analgesia (PCIA) using sufentanil (4 $\mu \mathrm{g} / \mathrm{kg}$ ) and tropisetron (10 mg), which was diluted with normal saline to $100 \mathrm{ml}$. The background dose was $2 \mathrm{ml} / \mathrm{h}$, and the patientcontrolled dose was $1 \mathrm{ml}$ each time, with a lockout period of 15 minutes.

The primary indicators were $P_{\text {plat }}, P_{\text {peak }}, C_{\text {dyn }}$ and arterial partial pressure of oxygen $\left(\mathrm{PaO}_{2}\right)$. $\mathrm{P}_{\text {plat' }}$, $P_{\text {peak }}, C_{\text {dyn }}$, stroke volume variability (SVV), cardiac index $(\mathrm{CI})$, central venous pressure (CVP) and MAP were measured at five minutes before OLV in a lateral position $\left(T_{1}\right), 30$ after OLV $\left(T_{2}\right)$ and 10 minutes after two-lung ventilation $\left(\mathrm{T}_{3}\right)$; blood gas analysis was performed for the arterial and venous blood samples collected at $T_{1}, T_{2}, T_{3}$ and two hours after surgery $\left(\mathrm{T}_{4}\right), \mathrm{PaO}_{2}$ and arterial partial pressure of carbon dioxide $\left(\mathrm{PaCO}_{2}\right)$ were recorded, and Qs/ Qt was calculated.

Secondary indicators: Venous blood was sampled at $T_{1}$ and 24 hours after surgery $\left(T_{7}\right)$. The concentrations of tumor necrosis factor- $\alpha$ (TNF- $\alpha$ ) and interleukin-6 (IL-6) were detected for each group using enzyme-linked immunosorbent assay (ELISA).
The pain scores at $T_{4}$ and six hours after surgery $\left(T_{6}\right)$ were assessed. Visual Analogue Scale (VAS) score and Ramsay Sedation Scale score at $T_{5}$ (four hours after surgery) were also assessed.

Respiratory and circulation complications were observed after surgery: pulmonary infection, pyothorax, atelectasis, pleural effusion, postoperative hypoxemia, arrhythmia and myocardial infarction.

\section{Statistical analysis}

Data were analyzed using the statistical software SPSS 17.0. Measurement data were expressed as mean \pm standard deviation $(x \pm S D)$. If the variance was homogeneous, inter-group comparison was conducted using a group $t$-test. If the variance was not homogeneous, inter-group comparison was conducted using the rank sum test. Intra-group comparison was conducted using repeated-measures analysis of variance. Count data were compared using Fisher's exact test and $p<0.05$ was considered statistically significant. Counting data were compared using the $\chi^{2}$ test and $p<0.05$ was considered statistically significant.

\section{Results}

(1) One hundred and thirty-two elderly patients with lung cancer were recruited. After excluding 12 patients, 120 patients were eligible (Figure 1).

There were no significant differences in gender, age, body mass index (BMI), ASA grading, and pulmonary function between the two groups $(p>0.05)$. Nor was there a significant difference in anesthesia duration, duration of surgery, duration of OLV, or intraoperative urine volume $(p>0.05)$ (Table I).

(2) Changes in respiratory mechanics and hemodynamic indicators in the two groups (Table II).

At $T_{2}$, compared with $T_{1}$, there was a significant decrease in SVV and $\mathrm{Cl}$ in the two groups ( $p<0.05)$. At $T_{2}$ and $T_{3}$, compared with group $C$, group $\mathrm{D}$ had a significant decrease in $\mathrm{Cl}$, MAP and CVP $(p<0.05)$. At $T_{2}$, compared with group $C$, group $D$ had a significant increase in SVV $(p<0.05)$. At $T_{2}$, compared with group $C$, group $D$ had a significant decrease in SVV $(p<0.05)$. There was no significant difference in intraoperative $\mathrm{P}_{\text {peak }}$ and $\mathrm{P}_{\text {plat }}$ between the two groups $(p>0.05)$.

(3) Changes in blood gas indicators in the two groups (Table III).

At $T_{2}, T_{3}$ and $T_{4}$, compared with group $C$, group $D$ had a significant increase in $\mathrm{pH}$ and $\mathrm{PaO}_{2}(p<0.05)$. At $T_{2}, T_{3}$ and $T_{4}$, compared with group $C$, group $D$ had a significant decrease in Qs/Qt $(p<0.05)$.

(4) Changes in TNF- $\alpha$ and IL- 6 concentrations in the two groups (Table IV).

At $T_{6}$, compared with group $C$, group $D$ had a significant decrease in the venous concentrations of TNF- $\alpha$ and IL- $6(p<0.05)$. 


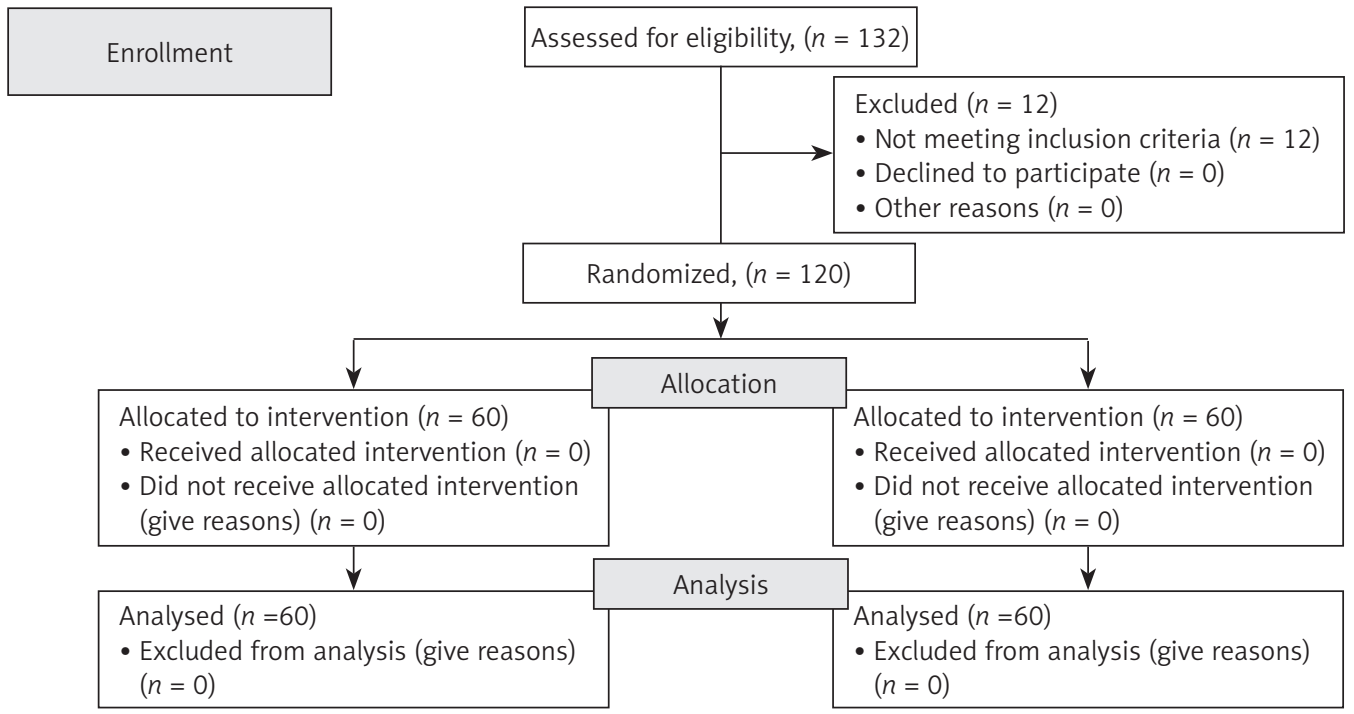

Figure 1. Flow diagram

Table I. General data of patients in the two groups and their conditions during the operation ( $n=60$ in each group)

\begin{tabular}{|lccc|}
\hline Item & Group D $(n=60)$ & Group C $(n=60)$ & $P$ \\
\hline Gender (male/female), $n$ & $34 / 26$ & $37 / 23$ & 0.067 \\
\hline Age [years] & $69.7 \pm 9.8$ & $70.6 \pm 11.5$ & 0.603 \\
\hline BMI [kg/m²] & $25.3 \pm 2.8$ & $24.8 \pm 2.9$ & 0.287 \\
\hline ASA (II/III) & $27 / 33$ & $28 / 32$ & 0.855 \\
\hline Smoking history (yes/no) & $40 / 20$ & $42 / 18$ & 0.422 \\
\hline Pulmonary function (\%) & & $107.7 \pm 25.5$ & 0.079 \\
\hline RV/TLC & $109.3 \pm 24.1$ & $2.0 \pm 0.4$ & 0.092 \\
\hline FEV ${ }_{1}$ & $1.8 \pm 0.5$ & $69.0 \pm 9.1$ & 0.312 \\
\hline FEV ${ }_{1} /$ FVC & $67.3 \pm 11.2$ & $18 / 42$ & 0.685 \\
\hline Thoracotomy location (left/right) & $16 / 44$ & $167.6 \pm 55.7$ & 0.304 \\
\hline OLV time [min] & $158.9 \pm 43.6$ & $223.0 \pm 60.9$ & 0.200 \\
\hline Operative time [min] & $209.3 \pm 65.7$ & $250.7 \pm 59.7$ & 0.110 \\
\hline Anesthesia time [min] & $232.6 \pm 57.8$ & $430.8 \pm 142.7$ & 0.298 \\
\hline Infused colloid [ml] & $406.3 \pm 120.4$ & $1200.1 \pm 319.6$ & 0.056 \\
\hline Infused crystalloid [ml] & $1277.4 \pm 300.8$ & $1.6 \pm 1.1$ & 0.741 \\
\hline Urine volume [ml/kg/h] & $1.5 \pm 0.9$ & $04 V-0 n e-14 n g v e n t a t o n$ & \\
\hline
\end{tabular}

$B M I$ - body mass index, FEV - forced expiratory volume in 1 second, FVC - forced vital capacity, OLV - one-lung ventilation.

(5) VAS and Ramsay Sedation Scale scores of the two groups (Table $V$ ).

At $T_{4}$ and $T_{5}$, compared with group $C$, group $D$ had a significant decrease in VAS score $(p<0.05)$, and significant increase in Ramsay Sedation Scale score $(p<0.05)$.

(6) Perioperative complications in the two groups (Table VI).

Compared with group C, the occurrence of respiratory and cardiovascular complications decreased significantly in group D $(p<0.05)$.
(7) Doses of each anesthetic used in the two groups (Table VII).

Compared with group C, the doses of propofol, cisatracurium and sufentanil decreased significantly in group D $(p<0.05)$, while the use of vasoactive agents increased $(p<0.05)$.

\section{Discussion}

Dexmedetomidine can decrease Qs/Qt and increase $\mathrm{PaO}_{2}$ during OLV and two hours after sur- 
Table II. Changes of respiratory mechanics and hemodynamics at different time points for the patients in both group $(\bar{x} \pm s)$

\begin{tabular}{|c|c|c|c|}
\hline Item & Group D $(n=60)$ & Group C $(n=60)$ & $P$ \\
\hline \multicolumn{4}{|c|}{$\mathrm{P}_{\text {plat }}\left[\mathrm{cm} \mathrm{H}_{2} \mathrm{O}\right]$} \\
\hline $\mathrm{T}_{1}$ & $17.6 \pm 1.6$ & $17.9 \pm 1.9$ & 0.330 \\
\hline $\mathrm{T}_{2}$ & $19.2 \pm 2.8$ & $19.9 \pm 3.8$ & 0.219 \\
\hline $\mathrm{T}_{3}$ & $18.1 \pm 2.7$ & $18.3 \pm 2.0$ & 0.379 \\
\hline \multicolumn{4}{|c|}{$\mathrm{P}_{\text {peak }}\left[\mathrm{cm} \mathrm{H} \mathrm{H}_{2} \mathrm{O}\right]$} \\
\hline $\mathrm{T}_{1}$ & $18.8 \pm 2.6$ & $19.1 \pm 2.8$ & 0.558 \\
\hline $\mathrm{T}_{2}$ & $20.8 \pm 4.0$ & $21.9 \pm 3.6$ & 0.155 \\
\hline $\mathrm{T}_{3}$ & $19.9 \pm 3.2$ & $20.8 \pm 3.4$ & 0.117 \\
\hline \multicolumn{4}{|c|}{ SVV (\%) } \\
\hline $\mathrm{T}_{1}$ & $11.0 \pm 1.8$ & $11.4 \pm 1.6$ & 0.157 \\
\hline $\mathrm{T}_{2}$ & $8.0 \pm 1.6$ & $7.1 \pm 1.7$ & 0.004 \\
\hline $\mathrm{T}_{3}$ & $9.1 \pm 2.1$ & $9.7 \pm 1.9$ & 0.061 \\
\hline \multicolumn{4}{|c|}{$\mathrm{Cl}\left[\mathrm{l} / \mathrm{min} / \mathrm{m}^{2}\right)$} \\
\hline $\mathrm{T}_{1}$ & $3.9 \pm 0.4$ & $4.1 \pm 0.5$ & 0.109 \\
\hline $\mathrm{T}_{2}$ & $3.2 \pm 0.6$ & $3.6 \pm 0.5$ & 0.000 \\
\hline $\mathrm{T}_{3}$ & $3.5 \pm 0.5$ & $3.7 \pm 0.4$ & 0.023 \\
\hline \multicolumn{4}{|c|}{ CVP $[\mathrm{mm} \mathrm{Hg}]$} \\
\hline $\mathrm{T}_{1}$ & $8.9 \pm 1.4$ & $8.5 \pm 1.3$ & 0.081 \\
\hline $\mathrm{T}_{2}$ & $9.4 \pm 1.6$ & $10.3 \pm 1.8$ & 0.003 \\
\hline $\mathrm{T}_{3}$ & $8.7 \pm 1.8$ & $9.3 \pm 2.3$ & 0.047 \\
\hline
\end{tabular}

MAP $[\mathrm{mm} \mathrm{Hg}]$

\begin{tabular}{cccc}
\hline $\mathrm{T}_{1}$ & $78.4 \pm 8.7$ & $76.6 \pm 10.4$ & 0.292 \\
\hline $\mathrm{T}_{2}$ & $69.9 \pm 9.0$ & $74.0 \pm 10.2$ & 0.024 \\
\hline $\mathrm{T}_{3}$ & $67.8 .2 \pm 8.5$ & $75.5 \pm 9.4$ & 0.000
\end{tabular}

$P_{\text {peak }}$ - inspiratory airway plateau pressure, $P_{\text {plat }}$ - inspiratory airway plateau pressure, $C_{d y n}$ - dynamic lung compliance, $C l$ - cardiac index, SVV - stroke volume variation, MAP - mean arterial pressure, CVP - central venous pressure.

Table IV. Changes in tumor necrosis factor- $\alpha$ (TNF- $\alpha$ ) and interleukine- 6 (IL- 6 ) concentrations in the two groups (pg/ml, $x \pm s$ )

\begin{tabular}{|cccc|}
\hline Item & Group D $(n=60)$ & Group C $(n=60)$ & $P$ \\
\hline TNF- $\alpha$ & & & \\
\hline $\mathrm{T}_{1}$ & $9.3 \pm 3.5$ & $9.7 \pm 3.4$ & 0.479 \\
\hline $\mathrm{T}_{6}$ & $14.9 \pm 1.8$ & $15.8 \pm 2.8$ & 0.048 \\
\hline $\mathrm{IL}-6$ & & & \\
\hline $\mathrm{T}_{1}$ & $15.6 \pm 2.6$ & $15.3 \pm 1.9$ & 0.420 \\
\hline $\mathrm{T}_{6}$ & $15.9 \pm 2.7$ & $16.8 \pm 2.4$ & 0.045 \\
\hline
\end{tabular}

Table III. Changes in blood gas indicators in the two groups $(\bar{x} \pm s)$

\begin{tabular}{|c|c|c|c|}
\hline Item & Group D $(n=60)$ & Group C $(n=60)$ & $P$ \\
\hline \multicolumn{4}{|l|}{$\mathrm{pH}$} \\
\hline $\mathrm{T}_{1}$ & $7.402 \pm 0.049$ & $7.395 \pm 0.045$ & 0.332 \\
\hline $\mathrm{T}_{2}$ & $7.417 \pm 0.042$ & $7.390 \pm 0.043$ & 0.000 \\
\hline $\mathrm{T}_{3}$ & $7.342 \pm 0.053$ & $7.373 \pm 0.047$ & 0.006 \\
\hline $\mathrm{T}_{4}$ & $7.376 \pm 0.037$ & $7.323 \pm 0.044$ & 0.000 \\
\hline \multicolumn{4}{|c|}{$\mathrm{PaCO}_{2}[\mathrm{~mm} \mathrm{Hg}]$} \\
\hline $\mathrm{T}_{1}$ & $35.6 \pm 6.4$ & $36.8 \pm 5.8$ & 0.237 \\
\hline $\mathrm{T}_{2}$ & $34.8 \pm 4.6$ & $34.8 \pm 4.8$ & 0.887 \\
\hline $\mathrm{T}_{3}$ & $33.8 \pm 4.5$ & $33.7 \pm 4.5$ & 0.292 \\
\hline $\mathrm{T}_{4}$ & $35.1 \pm 5.6$ & $35.4 \pm 5.3$ & 0.775 \\
\hline \multicolumn{4}{|c|}{ Qs/Qt (\%) } \\
\hline $\mathrm{T}_{1}$ & $12.1 \pm 1.8$ & $11.8 \pm 1.8$ & 0.093 \\
\hline $\mathrm{T}_{2}$ & $15.5 \pm 1.7$ & $18.3 \pm 2.3$ & 0.000 \\
\hline $\mathrm{T}_{3}$ & $13.5 \pm 1.8$ & $14.7 \pm 2.2$ & 0.008 \\
\hline $\mathrm{T}_{4}$ & $9.9 \pm 3.6$ & $11.7 \pm 2.8$ & 0.041 \\
\hline \multicolumn{4}{|c|}{$\mathrm{PaO}_{2}[\mathrm{~mm} \mathrm{Hg}]$} \\
\hline $\mathrm{T}_{1}$ & $472.5 \pm 69.2$ & $460.1 \pm 60.5$ & 0.067 \\
\hline $\mathrm{T}_{2}$ & $149.5 \pm 79.2$ & $144.1 \pm 81.5$ & 0.011 \\
\hline $\mathrm{T}_{3}$ & $354.8 \pm 84.3$ & $336.1 \pm 81.4$ & 0.028 \\
\hline $\mathrm{T}_{4}$ & $84.5 \pm 9.6$ & $83.5 \pm 10.0$ & 0.039 \\
\hline
\end{tabular}

Qs/Qt - intrapulmonary shunt

Table V. Visual Analogue Scale (VAS) and Ramsay Sedation Scale scores of the two groups $(x \pm s)$

\begin{tabular}{|cccc|}
\hline Item & Group D $(n=60)$ & Group C $(n=60)$ & $P$ \\
\hline VAS & & & \\
\hline $\mathrm{T}_{4}$ & $3.2 \pm 1.7$ & $4.7 \pm 1.6$ & 0.000 \\
\hline $\mathrm{T}_{5}$ & $4.5 \pm 1.3$ & $4.9 \pm 1.2$ & 0.025 \\
\hline Ramsay Sedation Scale & & \\
\hline $\mathrm{T}_{4}$ & $2.6 \pm 0.9$ & $1.5 \pm 0.6$ & 0.000 \\
\hline $\mathrm{T}_{5}$ & $1.6 \pm 0.6$ & $1.4 \pm 0.5$ & 0.016 \\
\hline
\end{tabular}

gery. Dexmedetomidine can decrease the bronchoalveolar lavage fluid (BALF) concentrations of TNF- $\alpha$ and IL- 6 at 24 hours after surgery in patients undergoing thoracotomy, thus further relieving lung injury. Dexmedetomidine can decrease pain scores at two hours and six hours after surgery. Dexmedetomidine also significantly reduced the intraoperative doses of propofol, sufentanil and cisatracurium. However, DEX 
Table VI. Perioperative complications in the two groups

\begin{tabular}{|c|c|c|c|}
\hline Item & Group D $(n=60)$ & Group C $(n=60)$ & $P$ \\
\hline \multicolumn{4}{|l|}{ Respiratory complications } \\
\hline Pulmonary infection & 3 & 4 & 0.500 \\
\hline Hypoxemia & 4 & 12 & 0.058 \\
\hline Atelectasis & 1 & 3 & 0.619 \\
\hline Asthma & 2 & 0 & 0.496 \\
\hline ALI/ARDS & 1 & 2 & 1.000 \\
\hline Total & 11 & 21 & 0.037 \\
\hline \multicolumn{4}{|l|}{ Cardiovascular complications } \\
\hline Arrhythmia & 6 & 11 & 0.295 \\
\hline Myocardial infarction & 0 & 1 & 1.000 \\
\hline Heart failure & 1 & 1 & 1.000 \\
\hline Hypertension & 12 & 17 & 0.394 \\
\hline Total & 19 & 30 & 0.041 \\
\hline
\end{tabular}

Table VII. Doses of anesthetics used in the two groups $(\bar{x} \pm s)$

\begin{tabular}{|lccc|}
\hline Item & Group D $(n=60)$ & Group C $(n=60)$ & $P$ \\
\hline Propofol [mg] & $648.9 \pm 145.0$ & $798.3 \pm 237.9$ & 0.000 \\
\hline Cisatracurium [mg] & $29.8 \pm 4.9$ & $33.2 \pm 5.9$ & 0.000 \\
\hline Sufentanil [mg] & $30.7 \pm 4.6$ & $34.8 \pm 5.6$ & 0.000 \\
\hline Remifentanil [mg] & $0.9 \pm 0.2$ & $1.3 \pm 0.3$ & 0.000 \\
\hline Ephedrine $(n)$ & 40 & 10 & 0.013 \\
\hline Atropine $(n)$ & 22 & 2 & \multirow{2}{*}{0.000} \\
\hline
\end{tabular}

caused a reduction in $\mathrm{Cl}, \mathrm{CVP}$ and MAP, which led to much higher doses of vasoactive agents during surgery. This deserves extra attention from anesthesiologists.

Qs/Qt remained low during OLV and at two hours after surgery in patients receiving DEX. The reasons may be as follows: (1) DEX relieves oxidative stress response of the lungs [18], thereby reducing lung injury caused by oxidative stress. Thus, better gas exchange in the lung is ensured after surgery; (2) it has been reported in the literature [10] that DEX could reduce Qs/Qt, thereby improving OI; (3) DEX has an analgesic effect [19], which is conducive to gas exchange of the lungs and to the prevention of hypoxemia; (4) DEX can reduce the dose of muscle relaxants, thereby reducing the residue of muscle relaxants after surgery. It has been reported in the literature [20] that the residue of muscle relaxants after surgery is great, which is correlated with postoperative complications. Therefore, the minimal residue of muscle relaxants after surgery can help achieve easier respiration and reduce the occurrence of hypoxemia postoperatively.

Neutrophils, alveolar macrophages and alveolar epithelial cells will produce a large number of inflammatory mediators after mechanical injury [21]. As a result, tissue injury will occur, as well as a large number of inflammatory mediators and inflammatory cells. Interleukin-6 is an important indicator of severity of early tissue injury [22]. Tumor necrosis factor- $\alpha$ is an important sensitive indicator of tissue injury [23]. Tumor necrosis factor- $\alpha$ and IL-6 are both important sensitive indexes to reflect the severity of lung tissue injury.

The BALF levels of TNF- $\alpha$ and IL- 6 can be used to assess pulmonary infection [24]. There have been many reports on TNF- $\alpha$ and IL- 6 in BALF as indicators for pulmonary inflammatory diseases $[25,26]$.

When mechanical injury occurs, neutrophils, alveolar macrophages and alveolar epithelial cells can produce a large number of inflammatory mediators, causing lung tissue damage. 
If there is a significant increase in the BALF levels of IL-6 and TNF- $\alpha$ after surgery, this usually indicates lung injury caused by thoracotomy and mechanical ventilation. However, DEX can inhibit the production of inflammatory factors, thereby relieving lung injury.

In our study, the pain scores decreased significantly at two hours and six hours after surgery. Sufficient analgesia is of particular importance in patients receiving thoracic surgery. As reported in the literature [27], postoperative hypoxemia and cardiovascular complications were closely correlated with insufficient postoperative analgesia, and proper analgesia could obviously reduce such occurrence. Due to the analgesic effect of DEX, the patients can breathe more easily after surgery, which helps reduce hypoxemia and $\mathrm{CO}_{2}$ accumulation and further improves the postoperative internal environment. Stability of the internal environment can reduce perioperative cardiovascular events.

The use of DEX could significantly reduce the intraoperative doses of propofol, cisatracurium and sufentanil. Propofol can increase intrapulmonary shunt, as was found in the DEX group in the present study. This helps reduce the postoperative residue of anesthetics. It has been reported in the literature [21] that the residue rate of muscle relaxants was up to $3.5-88 \%$ after surgery and that the postoperative complications were correlated with this. An overdose of opioids will inhibit respiration. In our study, the use of DEX significantly reduced the doses of muscle relaxants and opioids, which further reduced postoperative residues of muscle relaxants and opioids. Therefore, the patients were able to breathe more easily and had better gas exchange in the lungs.

Moreover, DEX stabilizes respiratory mechanics and hemodynamics, though the intraoperative incidence of sinus bradycardia increases considerably with a much higher use of intraoperative vasoactive agents. Dexmedetomidine is an $\alpha$-adrenergic receptor agonist, which agrees with the reported ability of DEX in reducing $\mathrm{BP}$ and $\mathrm{HP}$ [18]. This fact deserves extra attention from anesthesiologists.

The present study had the following limitations. First, a high fraction of inspiration $\mathrm{O}_{2}\left(\mathrm{FIO}_{2}\right)$ can possibly increase the risk of pulmonary atelectasis, lead to absent ventilation in low Qs/Qt of the lung and result in a large alveolar-arterial $\mathrm{O}_{2}$ tension difference [28]. Second, surgical trauma will also affect the lungs, leading to the generation of pro-inflammatory cytokines. Third, lung cancer patients already tend to have a higher level of cytokines before surgery, which will inevitably influence the results. Fourth, this is not a double-blinded study, and the anesthetist knew well about all patients. Thus, bias cannot be avoided.
In conclusion, in elderly patients, DEX can reduce Qs/Qt and improve the oxygenation index (OI) and reduce lung injury caused by OLV. Moreover, DEX reduces the perioperative cardiovascular complications, as well as the intraoperative doses of propofol, cisatracurium and sufentanil. The use of DEX can offer a certain protective effect for the lungs in elderly patients receiving thoracic surgery. However, the findings of the present study remain to be further validated.

\section{Conflicts of interest}

The authors declare no conflict of interest.

\section{References}

1. Gao W, Liu DD, Li D, et al. Effect of therapeutic hypercapnia on inflammatory responses to one-lung ventilation in lobectomy patients. Anesthesiology 2015; 122: 1235-52.

2. Huang SO, Zhang J, Zhang XX, et al. Can dexmedetomidine improve arterial oxygenation and intrapulmonary shunt during one-lung ventilation in adults undergoing thoracic surgery? A meta-analysis of randomized, placebo-controlled trials. Chin Med J (Engl) 2017; 130: 1707-14.

3. Okahara S, Shimizu K, Suzuki S, et al. Associations between intraoperative ventilator settings during onelung ventilation and postoperative pulmonary complications: a prospective observational study. BMC Anesthesiol 2018; 18: 13.

4. Naik BI, Colquhoun DA, Shields IA, et al. Value of the oxygenation index during 1-lung ventilation for predicting respiratory complications after thoracic surgery. J Crit Care 2017; 37: 80-4.

5. Blank RS, Colquhoun DA, Durieux ME, et al. Management of one-lung ventilation: impact of tidal volume on complications after thoracic surgery. Anesthesiology 2016; 124: 1286-95.

6. Zhang W, Zhang S, Li B, et al. Paravertebral dexmedetomidine as an adjuvant to ropivacaine protects against independent lung injury during one-lung ventilation: a preliminary randomized clinical trial. BMC Anesthesiol 2018; 18: 67.

7. Pfitzner J. Potential for acute lung injury following onelung ventilation: alveolar overdistension from partial bronchial obstruction. Anaesthesia 2010; 61: 906-7.

8. Amar D, Zhang H, Pedoto A, et al. Protective lung ventilation and morbidity after pulmonary resection: a propensity score-matched analysis. Anesth Analg 2017; 125: 190-9.

9. Olivant Fisher A, Husain K, Wolfson MR, et al. Hyperoxia during one lung ventilation: inflammatory and oxidative responses. Pediatr Pulmonol 2012; 47: 979-86.

10. Xia R, Xu J, Yin H, et al. Intravenous infusion of dexmedetomidine combined isoflurane inhalation reduces oxidative stress and potentiates hypoxia pulmonary vasoconstriction during one-lung ventilation in patients. Mediators Inflamm 2015; 2015: 238041.

11. Tsai CH, Lai YC, Chang SC, et al. Video-assisted thoracoscopic surgical decortication in the elderly with thoracic empyema: five years' experience. J Chin Med Assoc 2016; 79: 25-8.

12. Pfister D, Ang K, Brizel D. National Comprehensive Cancer Network (NCCN) Clinical Practice Guidelines in Oncology, 2012. 
13. Shiono S, Yoshida J, Nishimura M, et al. Risk factors of postoperative respiratory infections in lung cancer surgery. J Thorac Oncol 2007; 2: 34-8.

14. Shiono S, Abiko M, Sato T. Postoperative complications in elderly patients after lung cancer surgery. Interact Cardiovasc Thorac Surg 2013; 16: 819-23.

15. DeLuzio MR, Keshava HB, Wang Z, et al. A model for predicting prolonged length of stay in patients undergoing anatomical lung resection: a National Surgical Quality Improvement Program (NSQIP) database study. Interact Cardiovasc Thorac Surg 2016; 23: 208-15.

16. Li J, Chen Q He X, et al. Dexmedetomidine attenuates lung apoptosis induced by renal ischemia-reperfusion injury through 02AR/PI3K/Akt pathway. J TransI Med 2018; 16: 78 .

17. Yan X, Cheng X, Zhou L, et al. Dexmedetomidine alleviates lipopolysaccharide-induced lung injury in Wistar rats. Oncotarget 2017; 8: 44410-7.

18. Wu CY, Lu YF, Wang ML, et al. Effects of dexmedetomidine infusion on inflammatory responses and injury of lung tidal volume changes during one-lung ventilation in thoracoscopic surgery: a randomized controlled trial. Mediators Inflamm 2018; 2018: 2575910.

19. Wu C, Ma W, Cen Q, et al. A comparison of the incidence of supraventricular arrhythmias between thoracic paravertebral and intercostal nerve blocks in patients undergoing thoracoscopic surgery: a randomised trial. Eur J Anaesthesiol 2018; 35: 792-8.

20. Brull SJ, Murphy GS. Residual neuromuscular block: lessons unlearned. Part II: methods to reduce the risk of residual weakness. Anesth Analg 2010; 111: 129-40.

21. Schädler D, Pausch C, Heise D, et al. The effect of a novel extracorporeal cytokine hemoadsorption device on IL-6 elimination in septic patients: a randomized controlled trial. PLoS One 2017; 12: e0187015.

22. Mahmoud K, Ammar A, Kasemy Z. Comparison between pressure-regulated volume-controlled and volume-controlled ventilation on oxygenation parameters, airway pressures, and immune modulation during thoracic surgery. J Cardiothorac Vasc Anesth 2017; 31: 1760-6.

23. Patel BV, Wilson MR, O'Dea KP, et al. TNF-induced death signaling triggers alveolar epithelial dysfunction in acute lung injury. J Immunol 2013; 190: 4274-82.

24. Sharma AK, Mulloy DP, Le LT, et al. NADPH oxidase mediates synergistic effects of IL-17 and TNF- $\alpha$ on CXCL1 expression by epithelial cells after lung ischemia-reperfusion. Am J Physiol Lung Cell Mol Physiol 2014; 306: L69-79.

25. Schilling T, Kozian A, Senturk M, et al. Effects of volatile and intravenous anesthesia on the alveolar and systemic inflammatory response in thoracic surgical patients. Anesthesiology 2011; 115: 65-74.

26. You Z, Feng D, Xu H, et al. Nuclear factor-kappa B mediates one-lung ventilation-induced acute lung injury in rabbits. J Invest Surg 2012; 25: 78-85.

27. Bugada D, Lavand'homme P, Ambrosoli AL, et al. Effect of preoperative inflammatory status and comorbidities on pain resolution and persistent postsurgical pain after inguinal hernia repair. Mediators Inflamm 2016; 2016 5830347.

28. Kleinsasser AT, Pircher I, Truebsbach S, et al. Pulmonary function after emergence on $100 \%$ oxygen in patients with chronic obstructive pulmonary disease: a randomized, controlled trial. Anesthesiology 2014; 120: 1146-51. 